\title{
Fixed point theorems for generalized $\alpha-\psi$ type contractive mappings in b-metric spaces and applications
}

\author{
Xianbing $\mathrm{Wu}^{\mathrm{a}, *}$, Leina Zhao ${ }^{\mathrm{b}}$ \\ ${ }^{a}$ Department of Mathematics, Yangtze Normal University, Fuling, Chongqing 408100, P. R. China. \\ ${ }^{b}$ College of Mathematics and Statistics, Chongqing Jiaotong University, Chongqing, 400074, P. R. China.
}

\begin{abstract}
In this paper, we establish fixed point theorems for a new generalized $\alpha-\psi$ type contractive mapping in complete b-metric spaces. As applications of our results, we obtain fixed point theorems on metric space endowed with a partial order or a graph. We also obtain fixed point theorems for cyclic contractive mappings. Moreover, an application to integral equation is given here to illustrate the usability of the obtained results.
\end{abstract}

Keywords: $\alpha-\psi$ contractive mapping, b-metric space, fixed point theorem.

2010 MSC: 47H10, 47H09, 49J40.

(C)2018 All rights reserved.

\section{Introduction and preliminaries}

Fixed point theorems for $\alpha-\psi$ type contractive mappings in metric spaces were firstly obtained in 2012 by Samet et al. [29]. In this direction several authors obtained further results (see, e.g., [3-7, 16, 18, 19, 27, 31]).

Let $\Psi$ be family of functions $\psi:[0, \infty) \rightarrow[0, \infty)$ satisfying the following conditions:

(i) $\psi$ is increasing;

(ii) $\psi$ is continuous bijective;

(iii) $\lim _{n \rightarrow+\infty} \psi^{n}(t)=0$, for all $t \geqslant 0$, where $\psi^{n}$ is the $n$-th iterate of $\psi$.

It is easy to see that $\psi(t)<t$ for all $t>0$ and $\psi(0)=0$.

In this paper we denote $G(t)=t-\lambda s \psi(t), \lambda s \in(0,1]$. We easily obtain that $G$ is increasing continuous bijective, hence $\mathrm{G}^{-1}$ is increasing and continuous and $\mathrm{G}^{-1}(0)=0$.

Definition 1.1. Let $(X, d)$ be a metric space and $T: X \rightarrow X$ be a given mapping. We say that $T$ is an $\alpha-\psi$ contractive mapping if there exist two functions $\alpha: X \times X \rightarrow[0, \infty)$ and $\psi \in \Psi$ such that

$$
\alpha(x, y) d(T x, T y) \leqslant \psi(d(x, y)), \quad \forall x, y \in X
$$

\footnotetext{
${ }^{*}$ Corresponding author

Email addresses: flwxbing@163.com (Xianbing Wu), zhao_leina@163.com (Leina Zhao)

doi: $10.22436 /$ jmcs.018.01.06
} 
Clearly, any contractive mapping is an $\alpha-\psi$ contractive mapping with $\alpha(x, y)=1$ for all $x, y \in X$ and $\psi(t)=k t, k \in(0,1)$.

Definition 1.2. Let $T: X \rightarrow X$ and $\alpha: X \times X \rightarrow[0, \infty)$. We say that $T$ is an $\alpha$-admissible mapping if for all $x, y \in X$ we have the following implication:

$$
\alpha(x, y) \geqslant 1 \Rightarrow \alpha(T x, T y) \geqslant 1
$$

Definition 1.3. Let $T: X \rightarrow X$ and $\alpha: X \times X \rightarrow[0, \infty)$. We say that $T$ is a triangular $\alpha$-admissible mapping if for all $x, y, z \in X$ we have

$$
\alpha(x, y) \geqslant 1 \Rightarrow \alpha(T x, T y) \geqslant 1
$$

and

$$
\alpha(x, y) \geqslant 1, \alpha(y, z) \geqslant 1 \Rightarrow \alpha(x, z) \geqslant 1 .
$$

Various examples of the above mappings are presented in [16, 29] and [18].

Some results of fixed point in b-metric space have been obtained (see, e.g., [8, 9, 11, 12]). Now, we present some definitions in b-metric space.

Definition 1.4. Let $X$ be a nonempty set and the mapping $b: X \times X \rightarrow R^{+}$satisfies:

(b1) $b(x, y)=0$ if and only if $x=y$ for all $x, y \in X$;

(b2) $b(x, y)=b(y, x)$ for all $x, y \in X$;

(b3) there exists a real number $s \geqslant 1$ such that $b(x, y) \leqslant s[b(x, z)+b(z, y)]$ for all $x, y, z \in X$.

Then $b$ is called $a b$-metric on $X$ and $(X, b)$ is called a b-metric space with coefficient $s$.

Remark 1.5. It is clear that every metric space is a b-metric space with coefficient $s=1$.

Definition 1.6. Let $(X, b)$ be a b-metric space, then for $x \in X$ and $\epsilon>0$, the b-ball with center $x$ and radius $\epsilon$ is

$$
\mathrm{B}(x, \epsilon)=\{\mathrm{y} \in X \mid \mathrm{b}(x, y)<\varepsilon\} .
$$

Definition 1.7. Let $(X, b)$ be a b-metric space, $A \subset X$. $A$ is said to be a closed if and only if $x \in X$ and for all $\epsilon>0, B(x, \epsilon) \cap A \neq \phi$, then $x \in A$.

Definition 1.8. Let $(X, b)$ be a b-metric space, $A \subset X$. The diameter of $A$ is

$$
\delta(A)=\sup _{x, y \in A} b(x, y) .
$$

Definition 1.9 ([32]). A sequence $\left\{x_{n}\right\}$ in a b-metric space $(X, b)$ is said to be:

(i) a Cauchy sequence if and only if for all $\epsilon>0$ there exists $n(\epsilon) \in N$ such that for each $n, m \geqslant n(\epsilon)$ we have $b\left(x_{n}, x_{m}\right)<\epsilon$;

(ii) a convergent sequence if and only if there exists $x \in X$ such that for all $\epsilon>0$ there exists $n(\epsilon) \in N$ such that for each $n \geqslant n(\epsilon)$ we have $b\left(x_{n}, x\right)<\epsilon$.

Definition 1.10. A b-metric space $(X, b)$ is said to be complete if every Cauchy sequence $\left\{x_{n}\right\} \subset X$ converges to some $x \in X$.

Definition 1.11. Let $(X, b)$ be a b-metric space and $T: X \rightarrow X$ be a mapping. $T$ is continuous at $x \in X$, if and only if whenever $\left\{x_{n}\right\}$ is convergent to $x$, then $\left\{T x_{n}\right\}$ is convergent to $T x$. 


\section{Main results}

We introduce a new concept of generalized $\alpha-\psi$ contractive type mappings as follows.

Definition 2.1. Let $(X, d)$ be a metric space and $T: X \rightarrow X$ be a given mapping. We say that $T$ is a generalized $\alpha-\psi$ contractive mapping if there exist two functions $\alpha: X \times X \rightarrow[0, \infty), \psi \in \Psi$, for all $x, y \in X$ such that

$$
\alpha(x, y) d(T x, T y) \leqslant \psi(\max \{d(x, y), d(x, T x), d(y, T y), d(x, T y), d(y, T x)\}) .
$$

Remark 2.2. Since $\psi$ is increasing, clearly every $\alpha-\psi$ contractive mapping is generalized $\alpha-\psi$ contractive mapping.

Our results are the following.

Theorem 2.3. Let $(\mathrm{X}, \mathrm{b})$ be a complete b-metric space with coefficient $\mathrm{s} \geqslant 1$ and $\mathrm{T}: \mathrm{X} \rightarrow \mathrm{X}$ be a given mapping. If there exist a function $\psi \in \Psi$ and constant $\lambda \in\left(0, \frac{1}{s}\right]$, for all $x, y \in X$ such that

$$
\alpha(x, y) b(T x, T y) \leqslant \lambda \psi(\max \{b(x, y), b(x, T x), b(y, T y), b(x, T y), b(y, T x)\}),
$$

and which satisfies:

(i) T is triangular $\alpha$-admissible;

(ii) there exists $\mathrm{x}_{0} \in \mathrm{X}$ such that $\alpha\left(\mathrm{x}_{0}, \mathrm{~T} \mathrm{x}_{0}\right) \geqslant 1$;

(iii) $\mathrm{T}$ is continuous,

then $\mathrm{T}$ has a fixed point.

Proof. Let $x_{0} \in X$ such that $\alpha\left(x_{0}, T x_{0}\right) \geqslant 1$. Take $x_{n+1}=T x_{n}=T^{n} x_{0}$ for all $n \in N$. If $x_{n_{0}}=x_{n_{0}+1}$ for some $n_{0}$, then $x_{n_{0}}$ is a fixed point of $T$. So, we can assume that $x_{n+1} \neq x_{n}$ for all $n$. Since $T$ is triangular $\alpha$-admissible, we have

$$
\alpha\left(x_{0}, x_{1}\right)=\alpha\left(x_{0}, T x_{0}\right) \geqslant 1 \Rightarrow \alpha\left(T x_{0}, T x_{1}\right)=\alpha\left(x_{1}, x_{2}\right) \geqslant 1
$$

Moreover

$$
\alpha\left(x_{0}, x_{1}\right) \geqslant 1, \quad \alpha\left(x_{1}, x_{2}\right) \geqslant 1 \Rightarrow \alpha\left(x_{1}, x_{3}\right) \geqslant 1 .
$$

Inductively, for all $m, n \in N, n<m$, we easily obtain

$$
\alpha\left(x_{n}, x_{m}\right) \geqslant 1
$$

Let us denote $\mathrm{O}_{\mathrm{T}}\left(\mathrm{x}_{0} ; \mathrm{n}\right)=\left\{\mathrm{x}_{0}, T \mathrm{~T}_{0}, \cdots, \mathrm{T}^{\mathrm{n}} \mathrm{x}_{0}\right\}$ and $\delta \mathrm{O}_{\mathrm{T}}\left(\mathrm{x}_{0} ; \mathrm{n}\right)$ denotes the diameter of $\mathrm{O}_{\mathrm{T}}\left(\mathrm{x}_{0} ; \mathrm{n}\right)$. From (2.1) and (2.2), for each $1 \leqslant i<j \leqslant n, i, j \in N$, we have

$$
\begin{aligned}
\mathrm{b}\left(x_{i}, x_{j}\right) & =b\left(T x_{i-1}, T x_{j-1}\right) \\
& \leqslant \alpha\left(x_{i-1}, x_{j-1}\right) b\left(T x_{i-1}, T x_{j-1}\right) \\
& \leqslant \lambda \psi\left(\max \left\{b\left(x_{i-1}, x_{j-1}\right), b\left(x_{i-1}, x_{i}\right), b\left(x_{j-1}, x_{j}\right), b\left(x_{i-1}, x_{j}\right), b\left(x_{i}, x_{j-1}\right)\right\}\right) \\
& \leqslant \lambda \psi\left(\delta O_{T}\left(x_{0} ; n\right)\right) \\
& \leqslant \psi\left(\delta O_{T}\left(x_{0} ; n\right)\right) .
\end{aligned}
$$

It is easy to see that there exists $k \leqslant n, k \in N$ such that

$$
\mathrm{b}\left(\mathrm{x}_{0}, \mathrm{~T}^{\mathrm{k}} \mathrm{x}_{0}\right)=\delta \mathrm{O}_{\mathrm{T}}\left(\mathrm{x}_{0} ; \mathrm{n}\right) .
$$


Indeed, if there exists $i, j \neq 0, i<j$ such that $\delta \mathrm{O}_{\top}\left(x_{0} ; n\right)=b\left(x_{i}, x_{j}\right)$, from (2.4) we have

$$
\delta \mathrm{O}_{\mathrm{T}}\left(\mathrm{x}_{0} ; \mathrm{n}\right)=\mathrm{b}\left(\mathrm{x}_{\mathrm{i}}, \mathrm{x}_{\mathrm{j}}\right) \leqslant \psi\left(\delta \mathrm{O}_{\mathrm{T}}\left(\mathrm{x}_{0} ; \mathrm{n}\right)\right)<\delta \mathrm{O}_{\mathrm{T}}\left(\mathrm{x}_{0} ; \mathrm{n}\right) .
$$

It is a contradiction. Hence, by applying (2.3), (2.5) and the triangular inequality, we have

$$
\begin{aligned}
\delta \mathrm{O}_{\mathrm{T}}\left(\mathrm{x}_{0} ; \mathrm{n}\right) & =\mathrm{b}\left(\mathrm{x}_{0}, \mathrm{~T}^{\mathrm{k}} \mathrm{x}_{0}\right) \\
& \leqslant \mathrm{sb}\left(\mathrm{x}_{0}, \mathrm{~T} x_{0}\right)+\operatorname{sb}\left(\mathrm{T} x_{0}, \mathrm{~T}^{\mathrm{k}} x_{0}\right) \\
& \leqslant \mathrm{sb}\left(x_{0}, \mathrm{~T} x_{0}\right)+\operatorname{s} \lambda \psi\left(\delta \mathrm{O}_{\mathrm{T}}\left(x_{0} ; \mathrm{n}\right)\right),
\end{aligned}
$$

which leads to

$$
\delta \mathrm{O}_{\mathrm{T}}\left(\mathrm{x}_{0} ; \mathrm{n}\right)-\mathrm{s} \lambda \psi\left(\delta \mathrm{O}_{\mathrm{T}}\left(\mathrm{x}_{0} ; \mathrm{n}\right)\right) \leqslant \mathrm{sb}\left(\mathrm{x}_{0}, \mathrm{~T} \mathrm{x}_{0}\right) .
$$

For $G(t)=t-s \lambda \psi(t)$, since $G^{-1}$ is increasing, then

$$
\delta \mathrm{O}_{\mathrm{T}}\left(\mathrm{x}_{0} ; \mathrm{n}\right) \leqslant \mathrm{G}^{-1}\left(\mathrm{sb}\left(\mathrm{x}_{0}, \mathrm{~T} \mathrm{x}_{0}\right)\right) .
$$

Also, for all $m, n \in N$ and $m>n$, using (2.4), it results

$$
b\left(x_{n}, x_{m}\right) \leqslant \psi\left(r_{1}\right),
$$

where

$$
r_{1}=\delta O_{\mathrm{T}}\left(x_{n-1} ; m-n+1\right) .
$$

Now, by (2.5), there exists $k_{1} \in N, k_{1} \leqslant m-n+1$ such that

$$
r_{1}=\delta O_{T}\left(x_{n-1} ; m-n+1\right)=b\left(x_{n-1}, T^{k_{1}} x_{n-1}\right) \text {. }
$$

By using again (2.5) we have

$$
r_{1}=b\left(x_{n-1}, T^{k_{1}} x_{n-1}\right)=b\left(T x_{n-2}, T^{k_{1}+1} x_{n-2}\right) \leqslant \psi\left(r_{2}\right),
$$

where

$$
r_{2}=\delta O_{\mathrm{T}}\left(x_{n-2} ; k_{1}+1\right) .
$$

Since $\psi$ is monotone increasing and $k_{1}+1 \leqslant m-n+2$, from (2.7) and (2.8) we obtain

$$
b\left(x_{n}, x_{m}\right) \leqslant \psi^{2}\left(\delta O_{T}\left(x_{n-2} ; m-n+2\right)\right) .
$$

So, for all $m, n \in N$, and $m>n$, by induction, we get

$$
b\left(x_{n}, x_{m}\right) \leqslant \psi^{n}\left(\delta O_{T}\left(x_{0} ; m\right)\right) .
$$

By (2.6), we get

$$
b\left(x_{n}, x_{m}\right) \leqslant \psi^{n}\left(G^{-1}\left(\operatorname{sb}\left(x_{0}, T x_{0}\right)\right)\right) .
$$

Letting $n \rightarrow \infty$ in (2.9), we get

$$
\mathrm{b}\left(x_{n}, x_{m}\right) \rightarrow 0 .
$$

It implies $\left\{x_{n}\right\}$ is a Cauchy sequence, hence it is convergent. So there exists $x^{*} \in X$ such that

$$
\lim _{n \rightarrow \infty} b\left(x_{n}, x^{*}\right)=0 .
$$

Next we will show that $x^{*} \in F(T)$. Since $T$ is continuous, then $T x_{n} \rightarrow T x^{*}$ as $n \rightarrow \infty$. Using the triangular inequality, we have

$$
b\left(x^{*}, T x^{*}\right) \leqslant s b\left(x^{*}, x_{n+1}\right)+\operatorname{sb}\left(T x_{n}, T x^{*}\right) .
$$

Letting $n \rightarrow \infty$ in (2.12), we get $b\left(x^{*}, T x^{*}\right)=0$, which means $x^{*} \in F(T)$. 
Example 2.4. Let $X=[0, \infty)$, endow with the b-metric $b(x, y)=(x-y)^{2}$ with $s=2$ for all $x, y \in X$. Define the mapping $\mathrm{T}: \mathrm{X} \rightarrow \mathrm{X}$ by

$$
\mathrm{Tx}= \begin{cases}\frac{x}{4}, & x \in[0,1] \\ 2 x-\frac{7}{4}, & x \in(1, \infty) .\end{cases}
$$

We define the mapping $\alpha: X \times X \rightarrow[0, \infty)$ by

$$
\alpha(x, y)= \begin{cases}e^{|x-y|}, & \text { if } x, y \in\left(0, \frac{1}{4}\right] \\ e^{-|x-y|}, & \text { otherwise }\end{cases}
$$

Clearly, T is a triangular $\alpha$-admissible and generalized $\alpha-\psi$ contractive mapping with $\psi(t)=\frac{t}{4}$ for all $\mathrm{t} \in[0, \infty)$. In fact taking $\lambda=\frac{1}{4}$ for all $x, y \in X$, we have

$$
\alpha(x, y) b(T x, T y) \leqslant \lambda \psi(\max \{b(x, y), b(x, T x), b(y, T y), b(x, T y), b(y, T x)\}) .
$$

Moreover, there exists $x_{0}=\frac{1}{4} \in X$ such that

$$
\alpha\left(x_{0}, T x_{0}\right)=\alpha\left(\frac{1}{4}, \frac{1}{16}\right)=e^{\frac{3}{16}} \geqslant 1
$$

Obviously $\mathrm{T}$ is continuous.

Now, all the hypotheses of Theorem 2.3 are satisfied, T has a fixed point. In this example, 0 and $\frac{7}{4}$ are two fixed points of $\mathrm{T}$.

Theorem 2.5. Let $(\mathrm{X}, \mathrm{b})$ be a complete b-metric space with coefficient $\mathrm{s} \geqslant 1$ and $\mathrm{T}: \mathrm{X} \rightarrow \mathrm{X}$ be a given mapping. Suppose there exist a function $\psi \in \Psi$ and constant $\lambda \in\left(0, \frac{1}{s}\right]$, for all $x, y \in X$ such that

$$
\alpha(x, y) b(T x, T y) \leqslant \lambda \psi(\max \{b(x, y), b(x, T x), b(y, T y), b(x, T y), b(y, T x)\}),
$$

and which satisfies:

(i) T is triangular $\alpha$-admissible;

(ii) there exists $x_{0} \in X$ such that $\alpha\left(x_{0}, T x_{0}\right) \geqslant 1$;

(iii) if $\left\{x_{n}\right\}$ is a sequence in $(X, b)$ such that $\alpha\left(x_{n}, x_{n+1}\right) \geqslant 1$ for all $n \in N$ and $x_{n} \rightarrow x^{*} \in X$ as $n \rightarrow \infty$, then $\alpha\left(x_{n}, x^{*}\right) \geqslant 1$.

Then $\mathrm{T}$ has a fixed point.

Proof. Following the proof of Theorem 2.3, we know that the sequence $x_{n}$ defined by $x_{n+1}=T x_{n}$ for all $n \in N$, and converges to some $x^{*} \in X$. By applying (2.2) and condition (iii), we obtain $d\left(x_{n}, x^{*}\right) \geqslant 1$. So, by (2.1) and the triangular inequality, we have

$$
\begin{aligned}
b\left(x^{*}, T x^{*}\right) & \leqslant s b\left(x^{*}, x_{n+1}\right)+\operatorname{sb}\left(T x_{n}, T x^{*}\right) \\
& \leqslant s b\left(x^{*}, x_{n+1}\right)+s \alpha\left(x_{n}, x *\right) b\left(T x_{n}, T x^{*}\right) \\
& \leqslant s b\left(x^{*}, x_{n+1}\right)+s \lambda \psi\left(\max \left\{b\left(x_{n}, x^{*}\right), b\left(x_{n}, T x^{*}\right), b\left(x_{n+1}, x^{*}\right), b\left(x^{*}, T x^{*}\right), b\left(x_{n}, T x_{n}\right)\right\}\right) \\
& =s b\left(x^{*}, x_{n+1}\right)+s \lambda \psi(M)
\end{aligned}
$$

where

$$
M=\max \left\{b\left(x_{n}, x^{*}\right), b\left(x_{n}, T x^{*}\right), b\left(x_{n+1}, x^{*}\right), b\left(x^{*}, T x^{*}\right), b\left(x_{n}, T x_{n}\right)\right\} .
$$

There are three cases.

Case 1. If $M=\max \left\{b\left(x_{n}, x^{*}\right), b\left(x_{n+1}, x^{*}\right), b\left(x_{n}, x_{n+1}\right)\right\}$. 
Since $\psi$ is continuous, let $n \rightarrow \infty$ in (2.14). By (2.10) and (2.11) we get $b\left(x^{*}, T x^{*}\right)=0$.

Case 2. If $M=b\left(x^{*}, T x^{*}\right)$.

From (2.14), we have

$$
\mathrm{b}\left(\mathrm{x}^{*}, \mathrm{~T} x^{*}\right)-s \lambda \psi\left(\mathrm{b}\left(\mathrm{x}^{*}, \mathrm{~T} x^{*}\right)\right) \leqslant s b\left(x_{\mathrm{n}+1}, x^{*}\right),
$$

this implies $b\left(x^{*}, T x^{*}\right) \leqslant G^{-1}\left(s b\left(x_{n+1}, x^{*}\right)\right)$, since $G^{-1}$ is continuous and $G^{-1}(0)=0$, let $n \rightarrow \infty$, by $(2.11)$ we obtain $b\left(x^{*}, T x^{*}\right)=0$.

Case 3. If $M=b\left(x_{n}, T x^{*}\right)$.

Since $\psi$ is continuous, let $\mathrm{n} \rightarrow \infty$ in (2.14), by (2.11) we get

$$
\mathrm{b}\left(x^{*}, \mathrm{~T} x^{*}\right) \leqslant s \lambda \psi\left(\mathrm{b}\left(x^{*}, \mathrm{~T} x^{*}\right)\right) .
$$

This implies $b\left(x^{*}, T x^{*}\right)=0$, or

$$
\mathrm{b}\left(x^{*}, T x^{*}\right) \leqslant \psi\left(b\left(x^{*}, T x^{*}\right)\right)<b\left(x^{*}, T x^{*}\right) .
$$

It is a contradiction.

From the above three cases, we all obtain $b\left(x^{*}, T x^{*}\right)=0$, hence $x^{*}$ is a fixed point of $T$.

Example 2.6. Let $X=R$, endow with the b-metric $b(x, y)=(x-y)^{2}$ with $s=2$ for all $x, y \in X$. Define the mapping $\mathrm{T}: \mathrm{X} \rightarrow \mathrm{X}$ by

$$
\mathrm{T} x= \begin{cases}\frac{x}{4}, & x \in \mathrm{Q} \\ x^{2}-1, & x \in \mathrm{R}-\mathrm{Q} .\end{cases}
$$

We define the mapping $\alpha: X \times X \rightarrow[0, \infty)$ by

$$
\alpha(x, y)= \begin{cases}1, & \text { if } x, y \in Q \\ 0, & x \in R-Q\end{cases}
$$

Clearly, T is a triangular $\alpha$-admissible and generalized $\alpha-\psi$ contractive mapping with $\psi(t)=\frac{t}{4}$ for all $\mathrm{t} \in[0, \infty)$. In fact, taking $\lambda=\frac{1}{4}$ for all $x, y \in X$, we have

$$
\alpha(x, y) b(T x, T y) \leqslant \lambda \psi(\max \{b(x, y), b(x, T x), b(y, T y), b(x, T y), b(y, T x)\}) .
$$

Moreover, there exists $x_{0}=\frac{1}{4} \in X$ such that

$$
\alpha\left(x_{0}, T x_{0}\right)=\alpha\left(\frac{1}{4}, \frac{1}{16}\right)=1
$$

Take $x_{n}=T^{n} x_{0}$. We easily obtain

$$
\alpha\left(x_{n}, x_{n+1}\right)=\alpha\left(\frac{1}{4^{n}}, \frac{1}{4^{n+1}}\right)=1,
$$

and as $n \rightarrow \infty$, we have

$$
x_{n}=\frac{1}{4^{n}} \rightarrow x=0 \in X
$$

So

$$
\alpha\left(x_{n}, x\right)=\alpha\left(\frac{1}{4^{n}}, 0\right)=1 .
$$

Now, all the hypotheses of Theorem 2.5 are satisfied, $T$ has a fixed point. In this example, $0, \frac{1+\sqrt{5}}{2}$ and $\frac{1-\sqrt{5}}{2}$ are three fixed points of $\mathrm{T}$. 
(H) For all $x, y \in F(T)$, there exists $z \in X$ such that $\alpha(x, z) \geqslant 1$ and $\alpha(y, z) \geqslant 1$.

Theorem 2.7. Adding condition $(\mathrm{H})$ to Theorem 2.3 (resp., Theorem 2.5), then that $x^{*}$ is the unique fixed point of T.

Proof. Let that $x^{*}, y^{*} \in \mathrm{F}(\mathrm{T})$. By condition $(\mathrm{H})$, there exists $z \in \mathrm{X}$ such that

$$
\alpha\left(x^{*}, z\right) \geqslant 1, \quad \alpha\left(y^{*}, z\right) \geqslant 1 \text {. }
$$

Since $T$ is $\alpha$-admissible, from the above inequalities, for all $n \in N$, we obtain

$$
\alpha\left(x^{*}, T^{n} z\right) \geqslant 1, \quad \alpha\left(y^{*}, T^{n} z\right) \geqslant 1 .
$$

So

$$
\begin{aligned}
\mathrm{b}\left(x^{*}, \mathrm{~T}^{\mathrm{n}} z\right) & \leqslant \alpha\left(x^{*}, \mathrm{~T}^{\mathrm{n}-1} z\right) \mathrm{b}\left(\mathrm{T}^{\mathrm{n}} \chi^{*}, \mathrm{~T}^{\mathrm{n}} z\right) \\
& \leqslant \lambda \psi\left(\max \left\{\mathrm{b}\left(x^{*}, \mathrm{~T}^{\mathrm{n}-1} z\right), \mathrm{b}\left(\mathrm{T}^{\mathrm{n}-1} z, \mathrm{~T}^{\mathrm{n}} z\right), \mathrm{d}\left(\mathrm{x}^{*}, \mathrm{~T} x^{*}\right), \mathrm{b}\left(\mathrm{x}^{*}, \mathrm{~T}^{\mathrm{n}} z\right), \mathrm{b}\left(\mathrm{x}^{*}, \mathrm{~T}^{\mathrm{n}-1} z\right)\right\}\right) \\
& =\lambda \psi(\mathrm{N}) \\
& \leqslant \psi(\mathrm{N}),
\end{aligned}
$$

where

$$
N=\max \left\{b\left(x^{*}, T^{n-1} z\right), b\left(T^{n-1} z, T^{n} z\right), b\left(x^{*}, T x^{*}\right), b\left(x^{*}, T^{n} z\right), b\left(x^{*}, T^{n-1} z\right)\right\} .
$$

There are four cases.

Case 1. If $\mathrm{N}=\mathrm{b}\left(x^{*}, \mathrm{~T} x^{*}\right)$.

It implies for all $n \in N$, we have $b\left(x^{*}, T^{n} z\right)=0$.

Case 2. If $N=b\left(x^{*}, T^{n-1} z\right)$.

It results

$$
b\left(x^{*}, T^{n} z\right) \leqslant \psi\left(b\left(x^{*}, T^{n-1} z\right)\right),
$$

recursively, we obtain

$$
b\left(x^{*}, T^{n} z\right) \leqslant \psi^{n}\left(b\left(x^{*}, z\right)\right)
$$

Letting $n \rightarrow \infty$, we have

$$
\lim _{n \rightarrow \infty} b\left(x^{*}, T^{n} z\right)=0
$$

Case 3. If $\mathrm{N}=\mathrm{b}\left(\mathrm{x}^{*}, \mathrm{~T}^{\mathrm{n}} \mathrm{z}\right)$.

We get

$$
\mathrm{b}\left(\mathrm{x}^{*}, \mathrm{~T}^{\mathrm{n}} z\right) \leqslant \psi\left(\mathrm{b}\left(\mathrm{x}^{*}, \mathrm{~T}^{\mathrm{n}} z\right)\right) .
$$

It implies for all $n \in N$, we have $b\left(x^{*}, T^{n} z\right)=0$.

Case 4. If $\mathrm{N}=\mathrm{b}\left(\mathrm{T}^{\mathrm{n}-1} z, \mathrm{~T}^{\mathrm{n}} z\right)$.

Let $n \rightarrow \infty$ in (2.15). From (2.10) we obtain

$$
\lim _{n \rightarrow \infty} b\left(x^{*}, T^{n} z\right)=0
$$

From the above four cases, we all obtain

$$
\lim _{n \rightarrow \infty} b\left(x^{*}, T^{n} z\right)=0
$$

Similarly, we can get

$$
\lim _{n \rightarrow \infty} b\left(y^{*}, T^{n} z\right)=0 .
$$

Using the triangular inequality, we have

$$
b\left(x^{*}, y^{*}\right) \leqslant s b\left(x^{*}, T^{n} z\right)+s b\left(y^{*}, T^{n} z\right) .
$$

Letting $n \rightarrow \infty$, we get $b\left(x^{*}, y^{*}\right)=0$, i.e., $x^{*}=y *$. Hence $T$ has the unique fixed point. 


\section{Applications}

Next, we will show that some results can be deduced easily from our Theorem 2.7.

\subsection{Standard fixed point theorems}

Letting $s=1$ in Theorem 2.7, we may get the following fixed point theorem.

Corollary 3.1. Let $(X, d)$ be a complete metric space and $\mathrm{T}: \mathrm{X} \rightarrow \mathrm{X}$ be a mapping. If there exists a function $\psi \in \Psi$ for all $x, y \in X$ such that

$$
\alpha(x, y) d(T x, T y) \leqslant \psi(\max \{d(x, y), d(x, T x), d(y, T y), d(x, T y), d(y, T x)\}),
$$

and which satisfies:

(i) T is triangular $\alpha$-admissible;

(ii) there exists $x_{0} \in X$ such that $\alpha\left(x_{0}, T x_{0}\right) \geqslant 1$;

(iii) $T$ is continuous or if $\left\{x_{n}\right\}$ is a sequence in $(X, d)$ such that $\alpha\left(x_{n}, x_{n+1}\right) \geqslant 1$ for all $n \in N$ and $x_{n} \rightarrow x^{*} \in X$ as $n \rightarrow \infty$, then $\alpha\left(x_{n}, x^{*}\right) \geqslant 1$,

then

(1) Thas a fixed point;

(2) if the condition $(\mathrm{H})$ is satisfied, Thas a unique fixed point.

Letting $\alpha(x, y)=1$ in Theorem 2.7, for all $x, y \in X$, we get the following fixed point theorem.

Corollary 3.2. Let $(\mathrm{X}, \mathrm{b})$ be a complete $b$-metric space with coefficient $\mathrm{s} \geqslant 1$ and $\mathrm{T}: \mathrm{X} \rightarrow \mathrm{X}$ be a mapping. If there exist a function $\psi \in \Psi$ and constant $\lambda \in\left(0, \frac{1}{s}\right]$, for all $x, y \in X$ such that

$$
b(T x, T y) \leqslant \lambda \psi(\max \{b(x, y), b(x, T x), b(y, T y), b(x, T y), b(y, T x)\}),
$$

then T has a unique fixed point.

Corollary 3.3. Let $(X, d)$ be a complete metric space and $\mathrm{T}: \mathrm{X} \rightarrow \mathrm{X}$ be a mapping. If there exists a function $\psi \in \Psi$, for all $x, y \in X$ such that

$$
d(T x, T y) \leqslant \psi(\max \{d(x, y), d(x, T x), d(y, T y), d(x, T y), d(y, T x)\}),
$$

then $\mathrm{T}$ has a unique fixed point.

Corollary 3.4. Let $(\mathrm{X}, \mathrm{d})$ be a complete metric space and $\mathrm{T}: \mathrm{X} \rightarrow \mathrm{X}$ be a mapping. If there exist a function $\psi \in \Psi$ and constant $\mathrm{k} \in(0,1)$, for all $\mathrm{x}, \mathrm{y} \in \mathrm{X}$ such that

$$
d(T x, T y) \leqslant k \max \{d(x, y), d(x, T x), d(y, T y), d(x, T y), d(y, T x)\},
$$

then Thas a unique fixed point.

\subsection{Fixed point theorem on b-metric spaces endowed with a partial order}

Many exciting fixed point theorems on metric space with a partial have been obtained (see, e.g., $[1,13,20,24,25,28])$. According to our Theorem 2.7, we will deduce fixed point theorems on metric space with a partial, and know that those exciting theorems will be obtained easily by our result. At first, we present some concepts.

Definition 3.5. Let $(X, \preceq)$ be a partially ordered set, $T: X \rightarrow X$ be a mapping. We say that $T$ is increasing with respect to $\preceq$, if for all $x, y \in X$

$$
x \preceq y \Rightarrow T x \preceq T y .
$$


Definition 3.6. Let $(X, \preceq)$ be a partially ordered set. A sequence $\left\{x_{n}\right\} \subset X$ is said to be increasing with respect to $\preceq$, if $x_{n} \preceq x_{n+1}$ for all $n$.

Definition 3.7. Let $(X, \preceq, d)$ be partially ordered metric space. We say that $(X, \preceq, d)$ is regular if for every increasing sequence $\left\{x_{n}\right\} \subset X$ such that $x_{n} \rightarrow x \in X$ as $n \rightarrow \infty$, there exists a subsequence $\left\{x_{n(k)}\right\}$ of $\left\{x_{n}\right\}$ such that $x_{n(k)} \preceq x$ for all $k$.

We obtain the following result.

Corollary 3.8. Let $(\mathrm{X}, \preceq, \mathrm{b})$ be complete partially ordered b-metric space with coefficient $\mathrm{s} \geqslant 1$ and $\mathrm{T}: \mathrm{X} \rightarrow \mathrm{X}$ be an increasing mapping with respect to $\preceq$. Suppose there exist a function $\psi \in \Psi$ and constant $\lambda \in\left(0, \frac{1}{s}\right]$ such that

$$
d(T x, T y) \leqslant \lambda \psi(\max \{b(x, y), b(x, T x), b(y, T y), b(x, T y), b(y, T x)\})
$$

for all $x, y \in X$ with $x \succeq y$ and suppose the following conditions are satisfied:

(i) there exists $x_{0} \in X$ such that $x_{0} \preceq T x_{0}$.

(ii) $\mathrm{T}$ is continuous or $(\mathrm{X}, \preceq, \mathrm{b})$ is regular.

Then $\mathrm{T}$ has a fixed point. And, suppose for all $\mathrm{x}, \mathrm{y} \in \mathrm{X}$ there exists $z \in \mathrm{X}$ such that $\mathrm{x} \preceq \mathrm{y}$ and $\mathrm{y} \preceq z$, therefore the fixed point is unique.

Proof. Define the mapping $\alpha: X \times X \rightarrow[0, \infty)$ by

$$
\alpha(x, y)= \begin{cases}1, & \text { if } x \preceq y \text { or } x \succeq y, \\ 0, & \text { otherwise. }\end{cases}
$$

It is easy to see that $T$ is a generalized $\alpha-\psi$ contractive mapping, that is,

$$
\alpha(x, y) b(T x, T y) \leqslant \lambda \psi(\max \{b(x, y), b(x, T x), b(y, T y), b(x, T y), b(y, T x)\})
$$

for all $x, y \in X$. From condition (i), we have $\alpha\left(x_{0}, T x_{0}\right) \geqslant 1$. Moreover, for all $x, y \in X$, from the monotone property of $\mathrm{T}$, we have

$$
\alpha(x, y) \geqslant 1 \Rightarrow x \preceq y \quad \text { or } \quad x \succeq y \Rightarrow T x \succeq T y \quad \text { or } \quad T x \preceq T y \Rightarrow \alpha(T x, T y) \geqslant 1,
$$

and

$$
\alpha(x, y) \geqslant 1, \alpha(y, z) \geqslant 1 \Rightarrow x \preceq y \preceq z \quad \text { or } \quad x \succeq y \succeq z \Rightarrow \alpha(y, z) \geqslant 1
$$

Thus $\mathrm{T}$ is triangular $\alpha$-admissible. One the case that if $\mathrm{T}$ is continuous, then all the hypotheses of Theorem 2.3 are satisfied, so $T$ has a fixed point. The other case if that $(X, \preceq, b)$ is regular. Take $T x_{n}=x_{n}$, we may obtain $\alpha\left(x_{n}, x_{n+1}\right) \geqslant 1$, that is, $x_{n} \preceq x_{n+1}$ for all $n$ and $x_{n} \rightarrow x \in X$. Then there exists a subsequence $\left\{x_{n(k)}\right\}$ of $\left\{x_{n}\right\}$ such that $x_{n(k)} \preceq x$ for all $k$. This implies that $\alpha\left(x_{n(k)}, x\right) \geqslant 1$ for all $k$. Then all the hypotheses of Theorem 2.5 are satisfied. So T has a fixed point. Next, we show the uniqueness. By hypothesis for $x, y \in X$, there exists $z \in X$ such that $x \preceq y$ and $y \preceq z$. So we get $\alpha(x, z) \geqslant 1$ and $\alpha(y, z) \geqslant 1$. Hence the uniqueness of the fixed point is obtained from Theorem 2.7.

Corollary 3.9. Let $(\mathrm{X}, \preceq, \mathrm{d})$ be complete partially ordered metric space. Let $\mathrm{T}: \mathrm{X} \rightarrow \mathrm{X}$ be an increasing mapping with respect to $\preceq$. Suppose there exists a function $\psi \in \Psi$ such that

$$
d(T x, T y) \leqslant \psi(\max \{d(x, y), d(x, T x), d(y, T y), d(x, T y), d(y, T x)\})
$$

for all $\mathrm{x}, \mathrm{y} \in \mathrm{X}$ with $\mathrm{x} \succeq \mathrm{y}$. Suppose the following conditions are satisfied:

(i) there exists $x_{0} \in X$ such that $x_{0} \preceq T x_{0}$. 
(ii) $\mathrm{T}$ is continuous or $(\mathrm{X}, \preceq, \mathrm{d})$ is regular.

Then $\mathrm{T}$ has a fixed point. And, suppose for all $x, y \in X$ there exists $z \in X$ such that $x \preceq y$ and $y \preceq z$, so the fixed point is unique.

Corollary 3.10. Let $(X, \preceq, \mathrm{d})$ be complete partially ordered metric space. Let $\mathrm{T}: \mathrm{X} \rightarrow \mathrm{X}$ be an increasing mapping with respect to $\preceq$. Suppose there exists a constant $\mathrm{k} \in(0,1)$ such that

$$
d(T x, T y) \leqslant k \max \{d(x, y), d(x, T x), d(y, T y), d(x, T y), d(y, T x)\}
$$

for all $x, y \in X$ with $x \succeq y$. Suppose the following conditions are satisfied:

(i) there exists $x_{0} \in X$ such that $x_{0} \preceq T x_{0}$.

(ii) $\mathrm{T}$ is continuous or $(\mathrm{X}, \preceq, \mathrm{d})$ is regular.

Then $\mathrm{T}$ has a fixed point. And, suppose for all $\mathrm{x}, \mathrm{y} \in \mathrm{X}$ there exists $z \in \mathrm{X}$ such that $\mathrm{x} \preceq \mathrm{y}$ and $\mathrm{y} \preceq z$, so the fixed point is unique.

\subsection{Fixed point theorems for cyclic contractive mappings}

Some fixed point theorems for cyclic contractive mappings are obtained (see, e.g., [15, 17, 22, 23, 26, 32]). Next, we will show that some fixed point theorems for cyclic contractive mappings are obtained by our Corollary 3.2.

Corollary 3.11. Let $\left\{A_{i}\right\}_{i=1}^{2}$ be nonempty closed subsets of complete b-metric space $(X, b)$ with coefficient $s \geqslant 1$ and $\mathrm{T}: \mathrm{Y} \rightarrow \mathrm{Y}$ be a given mapping, where $\mathrm{Y}=\mathrm{A}_{1} \cup \mathrm{A}_{2}$. Suppose that the following conditions hold:

(i) $\mathrm{T}\left(\mathrm{A}_{1}\right) \subseteq A_{2}$ and $\mathrm{T}\left(\mathrm{A}_{2}\right) \subseteq A_{1}$;

(ii) there exist a function $\psi \in \Psi$ and constant $\lambda \in\left(0, \frac{1}{s}\right]$, for all $(x, y) \in A_{1} \times A_{2}$ such that

$$
b(T x, T y) \leqslant \lambda \psi(\max \{b(x, y), b(x, T x), b(y, T y), b(x, T y), b(y, T x)\}) .
$$

Then $\mathrm{T}$ has a unique fixed point that belongs to $A_{1} \cap A_{2}$.

Proof. Since $A_{1}$ and $A_{2}$ are closed subsets in the complete b-metric space $(X, b)$, then $(Y, b)$ is complete. So, all the conditions of Corollary 3.2 are satisfied. Thus we may get that $T$ has a unique fixed point, and it belongs to $A_{1} \cap A_{2}$ (from (i)).

Corollary 3.12. Let $\left\{\mathrm{A}_{\mathrm{i}}\right\}_{\mathrm{i}=1}^{2}$ be nonempty closed subsets of complete metric space $(\mathrm{X}, \mathrm{d}), \mathrm{T}: \mathrm{Y} \rightarrow \mathrm{Y}$ be a mapping, where $Y=A_{1} \cup A_{2}$. Suppose that the following conditions hold:

(i) $\mathrm{T}\left(\mathrm{A}_{1}\right) \subseteq \mathrm{A}_{2}$ and $\mathrm{T}\left(\mathrm{A}_{2}\right) \subseteq \mathrm{A}_{1}$;

(ii) there exists a function $\psi \in \Psi$, for all $(x, y) \in A_{1} \times A_{2}$ such that

$$
d(T x, T y) \leqslant \psi(\max \{d(x, y), d(x, T x), d(y, T y), d(x, T y), d(y, T x)\})
$$

Then $\mathrm{T}$ has a unique fixed point that belongs to $A_{1} \cap A_{2}$.

Corollary 3.13. Let $\left\{A_{i}\right\}_{i=1}^{2}$ be nonempty closed subsets of complete metric space $(X, d), T: Y \rightarrow Y$ be a mapping, where $Y=A_{1} \cup A_{2}$. Suppose that the following conditions hold:

(i) $\mathrm{T}\left(\mathrm{A}_{1}\right) \subseteq A_{2}$ and $\mathrm{T}\left(\mathrm{A}_{2}\right) \subseteq A_{1}$;

(ii) there exists constant $k \in(0,1)$, for all $(x, y) \in A_{1} \times A_{2}$ such that

$$
d(T x, T y) \leqslant k \max \{d(x, y), d(x, T x), d(y, T y), d(x, T y), d(y, T x)\} .
$$

Then $\mathrm{T}$ has a unique fixed point that belongs to $A_{1} \cap A_{2}$. 


\subsection{Fixed point theorem on metric spaces endowed with a graph}

Recently, Jachymski [14] obtained fixed point theorems on a metric space with a graph. Following the paper [14], some fixed point theorems on a metric space with a graph have appeared (see, e.g., [10, 21, 30]). At first, we need to introduce some concepts.

Let $(X, d)$ be a metric space and $\Delta$ be the diagonal of $X \times X$. Let $G$ be a directed graph such that the set $V(G)$ of its vertices coincides with $X$ and $\Delta \subseteq E(G), E(G)$ being the set of the edges of the graph. Assuming that $G$ has no parallel edges, we will suppose that $G$ can be identified with the $(V(G), E(G))$.

If $x$ and $y$ are vertices of $G$, then a path in $G$ from $x$ to $y$ of length $k \in N$ is a finite sequence $\left(x_{i}\right)_{0}^{k}$ of vertices such that $x_{0}=x, x_{k}=y$ and $\left(x_{i-1}, x_{i}\right) \in E(G)$, for $i \in\{1,2, \cdots, k\}$.

Let us denote by $\tilde{G}$ the undirected graph obtained from $G$ by ignoring the direction of edges. Notice that a graph $G$ is connected if there is a path between any two vertices and it is weakly connected if $\tilde{G}$ is connected.

The following results are obtained by Corollary 3.1.

Corollary 3.14. Let $(\mathrm{X}, \mathrm{d})$ be a metric space and $\mathrm{G}$ be a directed graph and $\mathrm{T}: \mathrm{X} \rightarrow \mathrm{X}$ be a given mapping. Suppose there exists a function $\psi \in \Psi$, for all $x, y \in E(G)$ such that

$$
d(T x, T y) \leqslant \psi(\max \{d(x, y), d(x, T x), d(y, T y), d(x, T y), d(y, T x)\}),
$$

and which satisfies:

(i) $(x, y) \in E(G) \Rightarrow(T x, T y) \in E(G)$, and $(x, y) \in E(G),(y, z) \in E(G) \Rightarrow(x, z) \in E(G)$;

(ii) there exists $\mathrm{x}_{0} \in \mathrm{X}$ such that $\left(\mathrm{x}_{0}, \mathrm{~T} \mathrm{x}_{0}\right) \in \mathrm{E}(\mathrm{G})$;

(iii) $T$ is continuous or if $\left\{x_{n}\right\}$ is a sequence in $(X, d)$ such that $\left(x_{n}, x_{n+1}\right) \in E(G)$ for all $n \in N$ and $x_{n} \rightarrow x^{*} \in X$ as $\mathrm{n} \rightarrow \infty$, then $\left(\mathrm{x}_{\mathrm{n}}, \mathrm{x}^{*}\right) \in \mathrm{E}(\mathrm{G})$.

Then

(1) Thas a fixed point;

(2) if $x, y \in F(T)$, there exists $z \in X$ such that $(x, y) \in E(G),(y, z) \in E(G)$, T has a unique fixed point.

Proof. Define the mapping $\alpha: X \times X \rightarrow[0, \infty)$ by

$$
\alpha(x, y)= \begin{cases}1, & \text { if } x, y \in E(G), \\ 0, & \text { otherwise, }\end{cases}
$$

which means all the hypotheses of Corollary 3.1 are satisfied. So we can deduce that $\mathrm{T}$ has a unique fixed point.

Corollary 3.15. Let $(\mathrm{X}, \mathrm{d})$ be a metric space and $\mathrm{G}$ be a directed graph and $\mathrm{T}: \mathrm{X} \rightarrow \mathrm{X}$ be a given mapping. Suppose there exists a constant $\mathrm{k} \in(0,1)$ for all $\mathrm{x}, \mathrm{y} \in \mathrm{E}(\mathrm{G})$ such that

$$
d(T x, T y) \leqslant k \max \{d(x, y), d(x, T x), d(y, T y), d(x, T y), d(y, T x)\},
$$

and which satisfies:

(i) $(x, y) \in E(G) \Rightarrow(T x, T y) \in E(G)$, and $(x, y) \in E(G),(y, z) \in E(G) \Rightarrow(x, z) \in E(G)$;

(ii) there exists $\mathrm{x}_{0} \in \mathrm{X}$ such that $\left(\mathrm{x}_{0}, \mathrm{~T} \mathrm{x}_{0}\right) \in \mathrm{E}(\mathrm{G})$;

(iii) $T$ is continuous or if $\left\{x_{n}\right\}$ is a sequence in $(X, d)$ such that $\left(x_{n}, x_{n+1}\right) \in E(G)$ for all $n \in N$ and $x_{n} \rightarrow x^{*} \in X$ as $\mathrm{n} \rightarrow \infty$, then $\left(\mathrm{x}_{\mathrm{n}}, \mathrm{x}^{*}\right) \in \mathrm{E}(\mathrm{G})$.

Then

(1) Thas a fixed point;

(2) if $x, y \in F(T)$, there exists $z \in X$ such that $(x, y) \in E(G),(y, z) \in E(G)$, T has a unique fixed point. 
3.5. Application to integral equations

Here, we are concerned with the nonlinear quadratic integral equation

$$
x(t)=h(t)+\theta \int_{0}^{t} k(t, s) f(s, x(s)) d s, \quad t \in[0, T], T>0 .
$$

Let $X=C([0, T])$ be the set of continuous functions in $[0, T]$ and

$$
b(x, y)=\sup _{t \in[0, T]}|x(t)-y(t)|^{p}, \quad x, y \in C([0, T]) .
$$

It is easy to see that $(X, b)$ is the complete $b$-metric space with $s=2^{p-1}, p \geqslant 1[2]$.

We consider (3.1) under the following assumptions:

(i) $\mathrm{h}:[0, \mathrm{~T}] \rightarrow \mathrm{R}$ is continuous;

(ii) $f:[0, T] \rightarrow R$ is continuous and for all $t \in[0, T]$, if $x \leqslant y$, we have

$$
f(t, x) \leqslant f(t, y), \quad|f(t, x)-f(t, y)| \leqslant L|x-y|,
$$

where $\mathrm{L}>0$ is a constant;

(iii) $\mathrm{k}:[0, \mathrm{~T}] \times[0, \mathrm{~T}] \rightarrow[0, \infty)$ is continuous and there exists a constant $\mathrm{K}>0$ such that

$$
\int_{0}^{t} k(t, s)|x(s)-y(s)| d s \leqslant K, \quad t \in[0, T]
$$

(iv) there exists $x_{0} \in X$ such that

$$
x_{0}(t)=h(t)+\theta \int_{0}^{t} k(t, s) f\left(s, x_{0}(s)\right) d s, \quad t \in[0, T], \quad T>0 .
$$

We have the following theorem.

Theorem 3.16. Suppose the above conditions (i)-(iv) are satisfied. If $\theta \mathrm{LKT}<\frac{1}{2^{p-1}}$, then the integral equation (3.1) has a unique continuous solution $x^{*} \in \mathrm{C}[0, \mathrm{~T}]$.

Proof. We consider the operator $\mathrm{T}: \mathrm{X} \rightarrow \mathrm{X}$ defined by

$$
T x(t)=h(t)+\theta \int_{0}^{t} k(t, s) f(s, x(s)) d s, \quad t \in[0, T], T>0 .
$$

We show that $T$ is an $\alpha-\psi$ generalized contractive mapping in b-metric spaces, that is,

$$
\alpha(x, y) b(T x(t), T y(t)) \leqslant \lambda \psi(M(x, y)),
$$

where $M(x, y)=\max \{d(x, y), d(x, T x), d(y, T y), d(x, T y), d(y, T x)\}$.

Now we let the function $\alpha: X \times X \rightarrow R$ defined by

$$
\alpha(x, y)= \begin{cases}1, & \text { if } x(t) \leqslant y(t), \quad t \in[0, T] \\ 0, & \text { otherwise }\end{cases}
$$

and the function $\psi:[0, \infty) \rightarrow[0, \infty)$ defined by

$$
\psi(t)=(\theta K L T)^{p-1} t, \quad t \in[0, \infty) .
$$


Obviously, $\psi \in \Psi$.

$$
b(T x(t), T y(t))=\sup _{t \in[0, T]}|T x(t)-T y(t)|^{p} .
$$

Also, if $x(t) \leqslant y(t)$ is not satisfied, then the inequality (3.3) holds immediately. So we may suppose $x(t) \leqslant y(t), t \in[0, T]$. From conditions (ii), (iii) and (3.2), we have

$$
\begin{aligned}
|T x(t)-T y(t)| & =\left|h(t)+\theta \int_{0}^{t} k(t, s) f(s, x(s)) d s-h(t)-\theta \int_{0}^{t} k(t, s) f(s, y(s)) d s\right| \\
& \leqslant \theta \int_{0}^{t} k(t, s)|f(s, x(s))-f(s, y(s))| d s \\
& \left.\leqslant \theta \int_{0}^{t} k(t, s) L \mid x(s)\right)-y(s) \mid d s \\
& \leqslant \theta K \operatorname{KL} \mid x(s))-y(s) \mid .
\end{aligned}
$$

So, from (3.4), we get

$$
b(T x(t), T y(t)) \leqslant(\theta K L T)^{p} b(x, y) \leqslant(\theta K L T)^{p} M(x, y) .
$$

Taking $\lambda=\theta K L T$ and by (3.5) we obtain

$$
\alpha(x, y) b(T x(t), T y(t)) \leqslant \lambda \psi(M(x, y)) .
$$

So, $T$ is an $\alpha-\psi$ generalized contractive mapping in b-metric spaces.

Take $x_{n}=T^{n} x_{0}, n \in N$. From condition (iv), we get $\alpha\left(x_{0}, T x_{0}\right)=1$. And from condition (ii) we may obtain

$$
\alpha(x, y)=1 \Rightarrow \alpha(T x, T y)=1
$$

So by induction, we get easily $\alpha\left(x_{n}, x_{n+1}\right)=1$. Also from the proof of Theorem 2.3, we know that $x_{n} \rightarrow x^{*} \in X$, then $\alpha\left(x_{n}, x^{*}\right)=1$. Hence all assumptions of Theorem 2.5 are satisfied. So, according to Theorem 2.5 we can deduce that $x^{*}$ is a fixed point of $T$, that is, $x^{*}$ is a solution to the integral equation (3.1).

Also, take $z(t)=\max \{x(t), y(t)\}, t \in[0, T]$. Then for all $x, y \in X$, there exists $z \in X$ such that $\alpha(x, z)=\alpha(y, z)=1$. From Theorem 2.7, we know that $x^{*}$ is the unique solution to the integral equation (3.1).

\section{Acknowledgment}

The first author is supported by the Educational Science Foundation of Chongqing, Chongqing of China (KG111309). The second author is supported by Chongqing City Board of Education (KJ1705136)

\section{References}

[1] R. P. Agarwal, M. A. El-Gebeily, D. O’Regan, Generalized contractions in partially ordered metric spaces, Appl. Anal., 87 (2008), 109-116. 3.2

[2] A. Aghajani, M. Abbas, J. R. Roshan, Common fixed point of generalized weak contractive mappings in partially ordered b-metric spaces, Math. Slovaca, 4 (2014), 941-960. 3.5

[3] H. Alikhani, V. Rakočević, S. Rezapour, N. Shahzad, Fixed points of proximinal valued $\beta$ - $\psi$-contractive multifunctions, J. Nonlinear Convex Anal., 16 (2015), 2491-2497. 1

[4] H. H. Alsulami, S. Chandok, M. A. Taoudi, I. M. Erhan, Some fixed point theorems for $(\alpha, \psi)$-rational type contractive mappings, Fixed Point Theory Appl., 2015 (2015), 12 pages.

[5] P. Amiri, S. Rezapour, N. Shahzad, Fixed points of generalized $\alpha-\psi$-contractions, Rev. R. Acad. Cienc. Exactas Fs. Nat. Ser. A Math. RACSAM, 108 (2014), 519-526. 
[6] J. H. Asl, S. Rezapour, N. Shahzad, On fixed points of $\alpha-\psi$-contractive multifunctions, Fixed Point Theory Appl., 2012 (2012), 6 pages.

[7] M. Berzig, E. Karapınar, Note on "Modified $\alpha-\psi$-contractive mappings with applications, Thai J. Math., 13 (2015), 147-152. 1

[8] M. Boriceanu, Fixed point theory for multivalued generalized contraction on a set with two b-metrics, Stud. Univ. BabeBolyai Math., 54 (2009), 3-14. 1

[9] M. Boriceanu, Strict fixed point theorems for multivalued operators in b-metric spaces, Int. J. Mod. Math., 4 (2009), 285-301. 1

[10] C. Chifu, G. Petruşel, Generalized contractions in metric spaces endowed with a graph, Fixed Point Theory Appl., 2012 (2012), 9 pages. 3.4

[11] S. Czerwik, Contraction mappings in b-metric spaces, Acta Math. Inform. Univ. Ostraviensis, 1 (1993), 5-11. 1

[12] S. Czerwik, Nonlinear set-valued contraction mappings in b-metric spaces, Atti Sem. Mat. Fis. Univ. Modena, 46 (1998), 263-276. 1

[13] J. Harjani, K. Sadarangani, Fixed point theorems for weakly contractive mappings in partially ordered sets, Nonlinear Anal., 71 (2009), 3403-3410. 3.2

[14] J. Jachymski, The contraction principle for mappings on a metric space with a graph, Proc. Amer. Math. Soc., 136 (2008), 1359-1373. 3.4

[15] E. Karapinar, Fixed point theory for cyclic weak $\phi$-contraction, Appl. Math. Lett., 24 (2011), 822-825. 3.3

[16] E. Karapınar, B. Samet, Generalized $\alpha-\psi$ contractive type mappings and related fixed point theorems with applications, Abstr. Appl. Anal., 2012 (2012), 11 pages. 1, 1

[17] W. A. Kirk, P. S. Srinivasan, P. Veeramani, Fixed points for mappings satisfying cyclical contractive conditions, Fixed Point Theory, 4 (2003), 79-89. 3.3

[18] A. Latif, M. Eshaghi Gordji, E. Karapınar, W. Sintunavarat, Fixed point results for generalized $(\alpha, \psi)$-Meir-Keeler contractive mappings and applications, J. Inequal. Appl., 2014 (2014), 11 pages. 1, 1

[19] B. Mohammadi, S. Rezapour, On modified $\alpha$ - $\phi$-contractions, J. Adv. Math. Stud., 6 (2013), 162-166. 1

[20] J. J. Nieto, R. Rodríguez-López, Contractive mapping theorems in partially ordered sets and applications to ordinary differential equations, Order, 22 (2005), 223-239. 3.2

[21] M. Öztürk, E. Girgin, On some fixed-point theorems for $\psi$-contraction on metric space involving a graph, J. Inequal. Appl., 2014 (2014), 10 pages. 3.4

[22] M. Păcurar, I. A. Rus, Fixed point theory for cyclic 申-contractions, Nonlinear Anal., 72 (2010), 1181-1187. 3.3

[23] M. A. Petric, Some results concerning cyclical contractive mappings, Gen. Math., 18 (2010), 213-226. 3.3

[24] A. Petruşel, I. A. Rus, Fixed point theorems in ordered L-spaces, Proc. Amer. Math. Soc., 134 (2006), 411-418. 3.2

[25] A. C. M. Ran, M. C. B. Reurings, A fixed point theorem in partially ordered sets and some applications to matrix equations, Proc. Amer. Math. Soc., 132 (2004), 1435-1443. 3.2

[26] I. A. Rus, Cyclic representations and fixed points, Ann. Tiberiu Popoviciu Semin. Funct. Equ. Approx. Convexity, 3 (2015), 171-178. 3.3

[27] P. Salimi, N. Hussain, A. Latif, Modified $\alpha-\psi$-contractive mappings with applications, Fixed Point Theory Appl., 2013 (2013), 19 pages. 1

[28] B. Samet, Coupled fixed point theorems for a generalized Meir-Keeler contraction in partially ordered metric spaces, Nonlinear Anal., 72 (2010), 4508-4517. 3.2

[29] B. Samet, C. Vetro, P. Vetro, Fixed point theorems for $\alpha-\psi$-contractive type mappings, Nonlinear Anal., 75 (2012), 2154-2165. 1, 1

[30] S. Shukla, Fixed point theorems of G-fuzzy contractions in fuzzy metric spaces endowed with a graph, Commun. Math., 22 (2014), 1-12. 3.4

[31] X.-B. Wu, Generalized $\alpha-\psi$ contractive mappings in partial b-metric spaces and related fixed point theorems, J. Nonlinear Sci. Appl., 9 (2016), 3255-3278. 1

[32] X.-B. Wu, L.-N. Zhao, Viscosity approximation methods for multivalued nonexpansive mappings, Mediterr. J. Math., 13 (2016), 2645-2657. 1.9, 3.3 